\title{
LA RESPONSABILIDAD DEL SOCIO DE UNA SECCIÓN COOPERATIVA: IMPUTACIÓN DE PÉRDIDAS Y DEUDA BANCARIA
}

\author{
Felipe Palau Ramírez \\ Catedrático de Derecho Mercantil \\ Centro de Investigación en Gestión de Empresas \\ Universitat Politècnica de València \\ https://orcid.org/0000-0003-1395-1799
}

\section{RESUMEN}

En el presente artículo se abordan cuestiones complejas y tan importantes como la responsabilidad de los socios por las deudas sociales y la imputación de las pérdidas. El sistema de responsabilidad en las sociedades es uno de los principios configuradores de su régimen jurídico, siendo fundamental la distinción entre la responsabilidad externa o frente a terceros de la sociedad y de los socios, de una parte, y de otra, la responsabilidad interna de los socios con la sociedad. La imputación de pérdidas y de deuda bancaria a los socios de una sección debe resolverse de conformidad con la ley de cooperativas estatal o autonómica aplicable y los estatutos de la sociedad cooperativa correspondiente. El principio de responsabilidad limitada de los socios por las deudas sociales no se aplica en sede de imputación de pérdidas $\mathrm{y}$, por consiguiente, no puede impedirse que los socios soporten las pérdidas de la cooperativa de forma personal e ilimitada, de forma proporcional a su participación en la actividad cooperativizada. Del mismo modo, los socios de una sección deben responder frente a la cooperativa por las pérdidas y la deuda derivada de la actividad diferenciada de la sección.

PALABRAS CLAVE: Cooperativa, socios, sección, responsabilidad, imputación de pérdidas, deuda.

CLAVES ECONLIT / ECONLIT DESCRIPTORS: K20, K22, J54, P13.

Cómo citar este artículo/How to cite this article: PALAU RAMÍREZ, F.: "La responsabilidad del socio de una sección cooperativa: imputación de pérdidas y deuda bancaria", CIRIEC-España, Revista Jurídica de Economía Social y Cooperativa, n 39, 2021, pp. 135-164.

DOI: 10.7203/CIRIEC-JUR.39.20776 


\section{THE LIABILITY OF THE COOPERATIVE SECTION PARTNER: IMPUTATION OF LOSSES AND BANK DEBT}

\section{EXPANDED ABSTRACT}

The article deals with complex and important issues such as the liability of the partners for corporate debts and the allocation of losses. The system of liability in companies is one of the principles shaping their legal regime, being fundamental the distinction between the external liability or liability towards third parties of the company, on the one hand, and on the other hand, the internal liability of the partners with the company.

As explained, and rather surprisingly because of the importance of the liability system from a typological point of view, the laws regulating cooperative societies not only follow different legal approaches, but even refer to the statutes of cooperative societies for the determination of the liability of members for corporate debts.

In view of the legislative differences existing between one Autonomous Community and another, the questions that arise, the imputation of losses and bank debt to the members of a section must be resolved in accordance with the applicable regional cooperative law and the statutes of the corresponding cooperative society. This complex issue is based on the distinction between the external liability regime of the cooperative and its members, and the internal liability or imputation of losses. All the laws expressly regulate the liability of the members, either in a dispositive or imperative manner. With one or the other character, the solution normally foreseen is that of no liability for social debts or liability limited to the contributions made to the capital of the cooperative regardless of whether or not they are paid up.

The internal liability of the members vis-à-vis the cooperative is distinct from the liability for social debts, as a case of external liability vis-à-vis third parties, which, in addition to covering cases in which they have acquired specific obligations with the cooperative, such as the obligations of permanence or the payment of passive dividends, includes the imputation of losses, whether they are ordinary or extraordinary cooperative losses, or extra-cooperative losses. The principle of limited liability of the members for the social debts does not apply to the imputation of losses and, therefore, these members cannot be prevented from bearing the losses of the cooperative in a personal and unlimited manner, in proportion to their participation in the cooperative activity. However, this is a controversial issue and some regional regulations limit liability. There are even court decisions that consider such limitation without an applicable legal rule providing for it. 
The autonomy of management of the sections, the need for their action not to prejudice the members of the cooperative who are not part of them, and the assumption by the members of the liability arising from the specific operations of each of the sections, makes it possible to understand that in order to demand liability from the members of a section it is unnecessary for the cooperative to have made prior disbursements, rather the cooperative is obliged to impute such debts: it is not a mere faculty. Thus, in the case of a cooperative society with debts arising from a section, the debts arising from the specific activity of the section must necessarily be imputed to the members of the section if the administrators act diligently. In addition, the cooperative will be able to demand such amounts at any time without waiting for the member to leave the cooperative.

In case of withdrawal of members of a section, the cooperative must demand from them the debt and losses originated by the specific activity of the section, proportionally to the cooperativized activity of the member. Otherwise, to the detriment of the members who remain in the section and continue to assume the risk of their specific activity and their debts to third parties, it would facilitate the escape of the universal liability of the member of the section towards the cooperative through the application of the open-door principle.

No distinction must be made as to the nature of the debts of the cooperative, or of the section, which are intended to be imputed to the members and, therefore, nothing prevents the imputable debt from being a bank debt, as any regional regulation expressly foreseen.

KEYWORDS: Cooperative, shareholders, section, responsibility, attribution of losses, debt. 
(pp. 135-164)

\section{SUMARIO}

I. Introducción. II. Responsabilidad de los socios e imputación de pérdidas. 1. Responsabilidad de la cooperativa y de los socios por las deudas sociales. 2. Responsabilidad de los socios frente a la cooperativa e imputación de pérdidas. 3. Responsabilidad de los socios de una sección e imputación de pérdidas. III. Imputación de pérdidas y obligaciones no vencidas al causar baja el socio de una sección. IV. Conclusiones. Bibliografía.

\section{Introducción}

La responsabilidad de los socios por las deudas sociales y la imputación de las pérdidas es de por sí una cuestión de gran complejidad, que se acentúa en el supuesto de baja del socio de una sección cooperativa cuando existen pérdidas o deudas que pueden imputarse a dicha sección. La resolución del problema exige una adecuada comprensión del sistema de responsabilidad en materia societaria y de uno de los principios configuradores de su régimen jurídico, como es la distinción entre la responsabilidad externa o frente a terceros de la sociedad y de los socios, de una parte, y de otra, la responsabilidad interna de los socios con la sociedad.

Pese a la importancia que el sistema de responsabilidad tiene desde un punto de vista tipológico, quien se aproxime por primera vez a las leyes reguladoras de las sociedades cooperativas, se sorprenderá de que las distintas leyes, no solo siguen distintas aproximaciones jurídicas a la responsabilidad de la sociedad cooperativa y de su socios, sino que incluso en numerosas ocasiones se remiten a los estatutos de las cooperativas para la determinación de la responsabilidad de los socios por las deudas sociales.

Por otra parte, pese a lo habitual de que estatutariamente se configuren distintas secciones en una cooperativa y se introduzca la obligatoriedad de que los socios se adscriban a una de ellas, las leyes cooperativas son más bien parcas en la regulación de las secciones y su régimen económico ${ }^{1}$.

1. En el presente trabajo se ha optado por tratar de forma acumulada la legislación estatal y autonómica cooperativa sin centrarse en una norma en concreto, por lo que su cita se hace en ocasiones a título de ejemplo de las distintas normas que abordan la cuestión en sentido similar, y en todo caso, por resultar conforme con los fundamentos y la argumentación que sirven de hilo conductor del trabajo. 
En efecto, la importancia de las secciones es de ver en las cooperativas del sector agroalimentario, en las que es habitual que se doten de una sección de crédito ${ }^{2}$, pero también de otras relativas a la actividad de producción hortofrutícola (OPFH) o a la actividad de comercialización de la producción. Así en el sector de la aceituna la creación de secciones de comercialización se ha considerado como alternativa a la integración para alcanzar los objetivos propuestos de incrementar la demanda de aceites de oliva vírgenes y acercar el conocimiento de los distintos tipos de aceites de oliva a los consumidores, implicando a la cooperativa en la distribución y en la obtención del valor añadido que esta fase genera ${ }^{3}$.

Pese a la importancia de las secciones, su regulación general en las distintas leyes cooperativas se reduce a un artículo y la responsabilidad u obligaciones de los socios a un párrafo (art. $5 \mathrm{LC}^{4}$, art. $14 \mathrm{LSCEx}^{5}$, art. $6 \mathrm{LSCAnd}^{6}$, art. $6 \mathrm{LCAr}^{7}$, art. $9 \mathrm{LC}$ $\mathrm{CLM}^{8}$, art. $6 \mathrm{LCCat}^{9}$ o art. $6 \mathrm{LCEus}^{10}$, entre otras), remitiéndose a los estatutos el detalle de sus reglas de funcionamiento ${ }^{11}$.

2. Sobre la importancia de las secciones de crédito en las cooperativas agroalimentarias, vid. CAMPOS CLIMENT, V., FAJARDO GARCÍA, I.G. \& SANCHIS PALACIO, J.R.: “Triple justificación de las secciones de crédito de las cooperativas agrarias de la Comunidad Valenciana: jurídica, económica y social”, CIRIECEspaña, Revista de Economía Pública Social y Cooperativa, no 54, 2006, pp. 129-166; y también FAJARDO GARCÍA, I.G.: "Las secciones de crédito en el ordenamiento jurídico español", CIRIEC-España, Revista de Economía Pública Social y Cooperativa, no 32, 1999, pp. 9-37. A su función de complementariedad para mejorar el desarrollo de las actividades en el sector agrario se refiere también GIRGADO PERANDONES, P.: "Capítulo IX. Las secciones de crédito de las sociedades cooperativas catalanas". En: Régimen jurídico de las sociedades cooperativas catalanas (Adaptado a la Ley 12/2015, de 9 de julio, de Cooperativas de Cataluña) (dir. ALFONSO SÁNCHEZ, R.), Atelier Editorial, Barcelona, 2020, pp. 279 y ss.

3. Evidentemente con el aumento de nivel de renta para los cooperativistas, vid. LATORRE RUIZ, J.: "El oportunismo de las secciones de comercialización en las sociedades cooperativas agrarias", Revista de Estudios Jurídicos, no 19, 2019, p. 251.

4. Ley 27/1999, de 16 de julio, de Cooperativas.

5. Ley 9/2018, de 30 de octubre, de sociedades cooperativas de Extremadura.

6. Ley 14/2011, de 23 de diciembre, de Sociedades Cooperativas Andaluzas.

7. Decreto Legislativo 2/2014, de 29 de agosto, del Gobierno de Aragón, por el que se aprueba el texto refundido de la Ley de Cooperativas de Aragón.

8. Ley 11/2010, de 4 de noviembre, de Cooperativas de Castilla-La Mancha.

9. Ley 12/2015, de 9 de julio, de cooperativas de Cataluńa.

10. Ley 11/2019, de 20 de diciembre, de Cooperativas de Euskadi.

11. No es objeto de este trabajo analizar las características de una sección, como tampoco lo es el análisis de las cooperativas de crédito o de vivienda, que tienen características específicas que las hacen merecedoras de un estudio separado, sin perjuicio de poder hacer a lo largo del trabajo alguna referencia a las secciones de las 
En el aislado precepto que las normas dedican a las secciones, solo se hace una somera mención a la responsabilidad de la sección y de los socios, que plantea dificultades interpretativas. Así, por ejemplo, y a expensas de su posterior análisis, en la norma más recientemente aprobada, como es la Ley de Cooperativas de Euskadi, solo se hace, dentro de la remisión a los estatutos para fijar el funcionamiento de la sección, la salvedad de que dichas reglas estatutarias, que pueden tener por objeto las "actividades económico-sociales específicas con autonomía de gestión", se fijarán "sin perjuicio de la responsabilidad general y unitaria de la cooperativa" (art. 6.1 LCEus). A esta previsión -que también contiene en su número 1- la Ley de Cooperativas de Aragón añade en el número 3 de su artículo 6: "Del cumplimiento de las obligaciones contraídas en el ejercicio de sus actividades específicas, responderán, en primer lugar, las aportaciones efectuadas o comprometidas por los socios integrados en la sección y, subsidiariamente, el patrimonio general de la cooperativa, que podrá repetir contra los socios de la sección para resarcirse de las cantidades desembolsadas por el cumplimiento de estas responsabilidades". Y Ley de Sociedades Cooperativas de Extremadura en un segundo párrafo del número 2 del artículo 14 recoge el siguiente ańadido: "En todo caso, persistirá la responsabilidad patrimonial universal de la sociedad cooperativa, con excusión del patrimonio de la sección afectada y con atención a las disposiciones que regulan la constitución por fases o promociones respecto de las sociedades cooperativas de viviendas".

Habida cuenta de las diferencias legislativas existentes entre una Comunidad Autónoma y otra, las cuestiones que se plantean, la imputación de pérdidas y, en concreto, de deuda bancaria a los socios de una sección deben resolverse de conformidad con la ley de cooperativas autonómica aplicable y los estatutos de la sociedad cooperativa correspondiente. Esta compleja tarea ha de partir de la distinción entre el régimen de responsabilidad externa de la cooperativa y de sus socios, y la responsabilidad interna o imputación de pérdidas. Todas las leyes regulan expresamente la responsabilidad de los socios, bien de forma dispositiva o imperativa. Con uno u

cooperativas de viviendas. Sobre la caracterización general de las secciones me permito recomendar el trabajo de MORILLAS JARILLO, M.J.: "Secciones (art. 12 LSCA)". En: Retos y oportunidades de las sociedades cooperativas andaluzas ante su nuevo marco legal (Comentario a la Ley 14/2011 de Sociedades Cooperativas Andaluzas y a su Reglamento de desarrollo (Decreto 123/2014) (dir. MORILLAS JARILLO, M.J., VARGAS VASSEROT, C. \& CANO ORTEGA, C.), Editorial Dykinson, Madrid, 2017, pp. 85 y ss. Véase también los trabajos de SANTOS MARTÍNEZ, V.: "Las secciones de las cooperativas en el Derecho español", Revista Jurídica de Catalunya (RJC), no 79(4) 1980, pp. 957-1010; GADEA SOLER, E.: "Las secciones de las cooperativas". En: Cooperativas agrarias y sociedades de transformación (coords. VARGAS VASSEROT, C. \& PULGAR EZQUERRA, J.), Editorial Dykinson, Madrid, 2006, pp. 605 y ss.; y DOMÍNGUEZ CABRERA, M.P.: "Responsabilidad patrimonial de las secciones de las cooperativas en proceso concursal", Aranzadi Civil: Revista Doctrinal, no 3, 2010, pp. 45 y ss. 
otro carácter, el régimen normalmente previsto es el de no responsabilidad por las deudas sociales o responsabilidad limitada a las aportaciones realizadas al capital de la cooperativa con independencia de que estén o no desembolsadas.

Distinta de la responsabilidad por las deudas sociales, en tanto supuesto de responsabilidad externa frente a terceros, es la responsabilidad interna de los socios frente a la cooperativa que, además de alcanzar a supuestos en que hayan adquirido específicas obligaciones con la cooperativa, como las obligaciones de permanencia, la realización de aportaciones suplementarias o el desembolso de dividendos pasivos, incluye la imputación de pérdidas, tanto se trate de pérdidas cooperativas ordinarias o extraordinarias, como de pérdidas extracooperativas. El principio de responsabilidad limitada de los socios por las deudas sociales no se aplica en sede de imputación de pérdidas y, por consiguiente, no puede impedirse que estos socios soporten las pérdidas de la cooperativa de forma personal e ilimitada, de forma proporcional a su participación en la actividad cooperativizada ${ }^{12}$.

\section{Responsabilidad de los socios e imputación de pérdidas}

\section{Responsabilidad de la cooperativa y de los socios por las deudas sociales}

La sociedad cooperativa responde de sus obligaciones con terceros con su propio patrimonio de forma ilimitada, como consecuencia de su personalidad jurídica y de acuerdo con el principio de responsabilidad patrimonial universal. Como se ha señalado por la doctrina en la materia ${ }^{13}$, ello es algo que solo recuerdan algunas normas

12. La SAP de Burgos de 31 de marzo de 2016 (TOL5.896.590) recoge alguno de los fundamentos de la responsabilidad ilimitada de los cooperativistas por las pérdidas: "Es generalizada la idea según la cual las ganancias que se generan por las actividades cooperativizadas que se realicen con los socios no son de la cooperativa sino que se han producido en el patrimonio del socio al que deben retornar, de ahí que, una vez que se acrediten esas ganancias o, mejor, excedentes a los socios -lo que se hace en proporción a la actividad cooperativizada realizada por cada socio con la cooperativa-, se hable de retorno cooperativo y de devolución -no distribución- del mismo. Y esta idea tiene un generalizado reconocimiento jurídico positivo en los arts. 58.4 de la Ley 27/1999, de 16 de Julio, de cooperativas (en lo sucesivo, LC ESTADO) y, por lo que al presente caso interesa, en el art. 74.4 de la Ley 4/2004, de 11 de abril, de Cooperativas de la Comunidad de Castilla y León (en lo sucesivo, LCCYL).

De la misma manera, las pérdidas derivadas de tales actividades no deben permanecer en la sociedad cooperativa, sino que han de imputarse a los socios en proporción a la actividad cooperativizada realizada por cada uno mediante un especial régimen de compensación o de imputación. Retorno y pérdidas se aplican con criterios de actividad cooperativizada y no en función de las aportaciones al capital social".

13. Vid. MORILLAS JARILLO, M.J. \& FELIÚ REY, M.I.: Curso de cooperativas, T. I., Editorial Tecnos, Madrid, 2018, p. 255. 
(ad. ex. arts. 53.1 LSCAnd, 4.2 LCAst ${ }^{14}, 7$ LCCan $^{15}$, 7.3 LCCLM, 5.1 LCCM ${ }^{16}, 4$ $\mathrm{LCRM}^{17}$ y $4.1 \mathrm{LCCV}^{18}$ ), sin duda por no ser necesario dado que se trata de una regla general de nuestro ordenamiento (art. 1911 Código Civil).

Además de la responsabilidad de la cooperativa como persona jurídica, las leyes reguladoras sujetan a los socios a un determinado régimen de responsabilidad que puede cambiar según la ley concreta que lo regula, la clase de cooperativa y el tipo de socio. La Ley de Cooperativas de Aragón es la única que incluye como contenido mínimo de los estatutos el régimen de responsabilidad de los socios por las deudas sociales [art. 9 j) LCAr], otras leyes como la de Castilla-La Mancha y Comunidad Valenciana solo exigen que conste en los estatutos si se establece un régimen de responsabilidad adicional o ilimitada [arts. 11 c) LCCM y 10.2 e) LCCV; obviamente también es dispositivo el régimen de responsabilidad en la normativa aragonesa, véase art. 47.1 LCAr]. Pero todas ellas regulan expresamente la responsabilidad de los socios, bien de forma dispositiva o imperativa (véase, con carácter imperativo, por ejemplo: art. 59 LCEus, art. 7.4 LCCLM, art. 4.3 LCAst o art. 69 LCCat). Con uno u otro carácter, el régimen normalmente previsto es el de no responsabilidad de los socios por las deudas sociales o responsabilidad limitada a las aportaciones realizadas al capital de la cooperativa con independencia de que estén o no desembolsadas ${ }^{19}$. De este modo, es de destacar cómo la sociedad cooperativa no se caracteriza por un tipo específico de responsabilidad externa asumido por sus socios, pero es común que los socios acuerden en sus estatutos que no asumen responsabilidad por las deudas sociales.

Entre otros supuestos especiales de responsabilidad del socio, como el del socio usuario o socio colaborador, la mayoría de las leyes regulan la responsabilidad del socio que deja de pertenecer a la cooperativa. Se trata, muchas veces, de un régimen de responsabilidad imperativo porque en las diferentes leyes cooperativas no se prevé la posible alteración de la norma por los estatutos ${ }^{20}$; estos, en consecuencia, se limi-

14. Ley 4/2010, de 29 de junio de Cooperativas del Principado de Asturias.

15. Ley 6/2013, de 6 de noviembre, de Cooperativas de Cantabria.

16. Ley 4/1999, de 30 de marzo, de Cooperativas de la Comunidad de Madrid.

17. Ley 8/2006, de 16 de noviembre, de Sociedades Cooperativas, de la Región de Murcia.

18. Decreto Legislativo $2 / 2015$, de 15 de mayo, del Consell, por el que aprueba el texto refundido de la Ley de Cooperativas de la Comunitat Valenciana.

19. Sobre los distintos regímenes de responsabilidad del socio, vid. MORILLAS JARILLO, M.J. \& FELIÚ REY, M.I., op. cit., pp. 256 y ss.; y FAJARDO GARCÍA, I.G.: La gestión económica de la cooperativa: responsabilidad de los socios, Editorial Tecnos, Madrid, 1997, pp. 213 y ss.

20. Una excepción se halla en el art. 41.3 LCCat que permite que en los estatutos se pueda establecer en caso de baja la responsabilidad del socio por "las inversiones realizadas y no amortizadas, en proporción a su acti- 
tan por lo general a repetir lo establecido en la Ley. La responsabilidad es limitada, al importe reembolsado o pendiente de reembolsar de las aportaciones del socio al capital social, y subsidiaria, únicamente se puede hacer efectiva previa excusión del haber social. Se limita también temporalmente en dos aspectos: la responsabilidad dura cinco ańos desde la pérdida de la condición de socio y alcanza únicamente a las deudas contraídas por la cooperativa con anterioridad a la baja del socio (ad. ex. art. 47.2 LCAr).

La responsabilidad por las deudas sociales en una cooperativa al uso se aproxima en gran medida a las sociedades de capital, en las que los socios no responden por las deudas sociales como consecuencia de la atribución de personalidad jurídica, como recoge el artículo 1, números 2 y 3, de Ley de Sociedades de Capital21 ${ }^{21}$ La responsabilidad del socio en caso de baja, se asemeja igualmente a la responsabilidad de los socios de las sociedades de responsabilidad limitada en los casos de reducción de capital mediante restitución de aportaciones, diferenciándose, principalmente, en que la responsabilidad de los socios de la sociedad de capital es solidaria entre sí y con la sociedad, y en que existe la posibilidad de dotar una reserva con cargo a beneficios o a reservas libres para excluir dicha responsabilidad solidaria ( $c f r$. art. 331 y 332 LSC; posibilidad esta última que tampoco es desconocida en el caso de baja de socios en el Derecho cooperativo, como es de ver en el artículo 55.5, párrafo 2, de la Ley de Cooperativas de Castilla-La Mancha).

vidad cooperativizada de los últimos cinco años. Como afirma COSTAS COMESAÑA, J.: "Capítulo VIII. Capital social, aportaciones y régimen económico”. En: Régimen jurídico de las sociedades cooperativas catalanas (Adaptado a la Ley 12/2015, de 9 de julio, de Cooperativas de Cataluña (dir. ALFONSO SÁNCHEZ, R.), Atelier Editorial, Barcelona, 2020, p. 276; se trata "de una responsabilidad patrimonial, de naturaleza contractual, directa del socio frente a la cooperativa y de carácter universal (art. 1911 C.c.); el socio responde de este incumplimiento o cumplimiento defectuoso de forma personal y con su patrimonio personal, presente of futuro".

21. Así ibid., p. 275; quien se remite para un análisis más profundo de este régimen de no responsabilidad de los socios por las deudas sociales a MORILLAS JARILLO, M.J. \& FELIÚ REY, M.I., op. cit., pp. 255 y ss. Sobre este tema me remito también al trabajo de ALFONSO SÁNCHEZ, R.: "Sociedad y socios como legitimados activos en la solicitud de declaración de concurso de sociedades cooperativas", Revista de Derecho de Sociedades (RdS), no 43, 2014, pp. 85-117; que en las páginas 99 y siguientes analiza la responsabilidad limitada del socio cooperativo conforme al art. 15.3 de la Ley de Cooperativas estatal y la responsabilidad del socio comanditario del art. 148.3 del Código, concluyendo que puede afirmarse que los socios son personalmente responsables hasta el límite de la aportación social comprometida, lo que tiene efectos concursales por cuanto podrán solicitar el concurso de la cooperativa; analiza también la autora con detalle la naturaleza de la acción -subrogatoria o directa- que tendrían los terceros contra el socio que no haya realizado la aportación a la cooperativa. Más recientemente, de esta última autora, véase su trabajo: ALFONSO SÁNCHEZ, R.: "Régimen de responsabilidad del socio". En: La Ley 27/1999, de 16 de julio, de cooperativas [Veinte años de vigencia y resoluciones judiciales (1999.2019)] (dirs. ALFONSO SÁNCHEZ, R., CAVAS MARTÍNEZ, F., NAVARRO EGEA, M. \& VALERO TORRIJOS, J.), Editorial Aranzadi, Cizur Menor, 2021, pp. 463 y ss. 
A continuación, se detiene la atención en la responsabilidad del socio frente a la cooperativa y en la imputación de pérdidas, así como en la imputación al socio de una sección cooperativa de las pérdidas o deudas sociales, que tiene un mayor alcance que el régimen general de responsabilidad expuesto.

\section{Responsabilidad de los socios frente a la cooperativa e imputación de pérdidas}

Distinta de la responsabilidad por las deudas sociales, en tanto supuesto de responsabilidad externa frente a terceros, es la responsabilidad interna de los socios frente a la cooperativa ${ }^{22}$ que, además de alcanzar a supuestos en que hayan adquirido específicas obligaciones con la cooperativa, como las mencionadas obligaciones de permanencia o el desembolso de dividendos pasivos, incluye la imputación de pérdidas, tanto se trate de pérdidas cooperativas ordinarias o extraordinarias, como de pérdidas extracooperativas ${ }^{23}$.

Las leyes cooperativas establecen las reglas conforme a las que se imputan las pérdidas del ejercicio, permitiendo que los estatutos fijen las mismas. Suelen seguir esta distinción y no todas las leyes permiten imputar las pérdidas de la actividad extracooperativa a los socios ${ }^{24}$. Así es, por ejemplo, el caso de la Ley aragonesa que, al establecer las reglas para la imputación de las pérdidas del ejercicio económico, distingue entre las pérdidas que provienen de la actividad cooperativizada y otras pérdidas societarias o extracooperativas. Interesa ahora destacar la regla de esta norma autonómica a cuyo tenor: "Las pérdidas asumidas por la asamblea general y no compensadas serán consideradas como un crédito a favor de la cooperativa, que podrá ser

22. Como señala COSTAS COMESAÑA, J., op. cit., p. 275; se trata esta de una cuestión que ha dado lugar a posiciones enfrentadas en la doctrina. Sobre esta cuestión remite el autor a los trabajos de PANIAGUA ZURERA, M.: Tratado de Derecho Mercantil, t. XII: La sociedad cooperativa. Las sociedades mutuas de seguros y las mutualidades de previsión social, Marcial Pons, Ediciones Jurídicas y Sociales, Madrid, 2005, pp. 879 y ss.; y VARGAS VASSEROT, C., GADEA SOLER, E. \& SACRISTÁN BERGIA, F.: Derecho de las sociedades cooperativas. Régimen económico, integración, modificaciones estructurales y disolución, La Ley, Madrid, 2017, pp. 177 y ss.; quienes parten de la imputación de pérdidas como un sistema de saneamiento empresarial compatible con la responsabilidad limitada de los socios.

23. Conforme señalan MORILLAS JARILLO, M.J. \& FELIÚ REY, M.I., op. cit., pp. 551 y ss.; algunas leyes imponen y otras omiten el requisito de distinguir las pérdidas derivadas de la actividad realizada con los socios, las de la actividad cooperativizada realizada con terceros y las que se originan en actividades extraordinarias.

24. Para una referencia a las leyes que hacen esta distinción, y que no permiten imputar estas últimas a los socios, sino a su compensación con cargo a un fondo de reserva, vid. GADEA SOLER, E., SACRISTÁN BERGIA, F. \& VARGAS VASSEROT, C.: Régimen jurídico de la sociedad cooperativa del siglo XXI. Realidad actual y propuestas de reforma, Editorial Dykinson, Madrid, 2009, pp. 506 y ss. 
ejercitado aunque el socio haya causado baja voluntaria u obligatoria en la misma" [art. 58.5 e) LCAr]. En la misma línea, en la Ley castellano-manchega para el caso de que se haya previsto por la asamblea la satisfacción de las pérdidas imputadas al socio con cargo a los retornos que le pueden corresponder en los siete años siguientes, se prevé: "Si quedasen pérdidas sin compensar, transcurrido dicho período, estas deberán ser satisfechas por el socio en el plazo máximo de un mes a partir del requerimiento expreso formulado por el órgano de administración" [art. 89.3 b) LCCLM]. Se trata, pues, de un crédito cuya facultad de cobro se otorga a los administradores en cualquier momento transcurrido el plazo de tiempo para la compensación previsto por la asamblea. Puede entenderse que los socios han cobrado un sobreprecio que la cooperativa debe recuperar, planteándose su recuperación la mayoría de las veces en el momento de baja del socio.

Las leyes cooperativas regulan con detalle las reglas de imputación al socio de las pérdidas (art. 89 LCCV o 58 LCAr), que no se considera necesario reproducir, pero sí es oportuno recordar que la razón de la atribución de las pérdidas a los socios radica en el carácter mutualístico de las cooperativas, en la concepción tradicional según la cual el excedente y la pérdida de la cooperativa "se han originado en el ejercicio de una actividad realizada por cuenta del socio. Es la misma razón que justifica el derecho del socio a los excedentes obtenidos en uso de la cooperativa" 25 .

La imputación de pérdidas al socio, por ejemplo, mediante su forma más habitual que son las derramas obligatorias, conlleva una aportación patrimonial a la cooperativa que no constituye aportación al capital; dichas derramas no se contabilizan como aportaciones, sino que van destinadas a compensación del saldo negativo. No se trata, pues, de un supuesto de responsabilidad de los socios por las deudas sociales y, por tanto, limitada a las aportaciones realizadas a la sociedad. Se trata de un sistema de compensación de pérdidas de la cooperativa en el ámbito interno que debe permitir recuperar su liquidez y evitar la disminución del pasivo exigible de la sociedad ${ }^{26}$. El principio de responsabilidad limitada de los socios por las deudas sociales no se aplica en sede de imputación de pérdidas y, por consiguiente, no puede impedirse que estos socios soporten las pérdidas de la cooperativa de forma personal e ilimitada, de forma

25. Vid. FAJARDO GARCÍA, I.G.: La gestión..., p. 183; LLOBREGAT HURTADO, M.L.: "Posición jurídica del socio (I): clases de socios, adquisición de la condición de socio, derechos y obligaciones y responsabilidad". En: La Sociedad Cooperativa en la Ley 27/1999, de 16 de julio, de Cooperativas (coord. ALONSO ESPINOSA, F.J.), Editorial Comares, Granada, 2001, pp. 188 y ss. Y más recientemente véanse los trabajos de ALFONSO SÁNCHEZ, R.: “Sociedad...”, pp. 85-117; e ibid.: “Régimen...”, pp. 463 y ss.; especialmente este trabajo que cuenta con las más recientes decisiones de nuestros tribunales sobre el tema.

26. Vid. BORJABAD GONZALO, P.J.: Manual de Derecho cooperativo. Generaly catalán, J. M. Bosch Editor, Barcelona, 1993, p. 134. 
proporcional a su participación en la actividad cooperativizada ${ }^{27}$. De no imputarse las pérdidas conforme a la actividad cooperativizada del socio se estaría poniendo en peligro la estabilidad y continuidad de la cooperativa.

Esta es una cuestión clara en nuestra legislación cooperativa, que, sin embargo, ha causado confusión en la doctrina, entre los prácticos del derecho e, incluso, entre nuestros tribunales, que han querido aplicar la limitación de responsabilidad por las deudas sociales a la imputación de pérdidas, sobre todo en casos de baja de socios, al entender erróneamente que las referencias legislativas a la responsabilidad del socio saliente durante 5 años hasta el límite del importe reembolsado por sus aportaciones también se aplica a las pérdidas imputables. Esta confusión es destacada por la profesora FAJARDO, en los siguientes términos: "la confusión entre responsabilidad por las pérdidas ordinarias cooperativas y la responsabilidad de los socios por las deudas sociales es muy frecuente en la doctrina y entre los prácticos del Derecho cooperativo. Se señala frecuentemente que el socio participa en las pérdidas ordinarias cooperativas, pero de forma limitada a su responsabilidad por las deudas sociales. Esto puede ser una legítima aspiración, pero que, desde luego, no se desprende del análisis de nuestra legislación cooperativa" ${ }^{28}$. El importe de la imputación de pérdidas de la cooperativa al socio (esfera interna de responsabilidad) no resulta afectada por la limitación de responsabilidad por las deudas sociales (esfera externa de responsabilidad), que no podrá exceder de la cuantía reembolsada en caso de baja del socio de la sociedad.

Afortunadamente, existe algún pronunciamiento de nuestros tribunales muy clarificador en este sentido. El Tribunal Supremo en su sentencia de 2 de marzo de $2011^{29}$, que confirma la sentencia de la Audiencia Provincial de Jaén (Sección 1a) de 8 de febrero de $2007^{30}$, estima que los sobreprecios pagados a sus socios deben considerarse pérdidas y "por tanto no puede quedar limitada (la imputación de pérdidas) por sus aportaciones al capital social”. Y añade que la limitación de responsabilidad opera "respecto a las deudas de la cooperativa con terceros, no respecto a las relaciones internas de la sociedad y el socio" 31 .

27. Así se pronuncia una de las voces de más prestigio en materia cooperativa, vid. VICENT CHULIÁ, F.: Introducción al Derecho mercantil, vol. I, Editorial Tirant lo Blanch, València, 2012, pp. 1187 y 1191.

28. Vid. FAJARDO GARCÍA, I.G.: La gestión..., p. 244.

29. R. Ar. 2618.

30. R. Ar. 265757.

31. Véase sobre la importancia de esta sentencia, PANIAGUA ZURERA, M.: "Régimen económico". En: Tratado de Derecho de sociedades cooperativas (dir. PEINADO GARCÍA, J.I.), T. I, Editorial Tirant Lo Blanch, València, 2018, p. 883. 
Y así es de ver también en la sentencia de la Audiencia Provincial de Jaén (Sección $1^{\text {a) }}$ de 28 de abril de $2011^{32}$, que, en relación con la Ley anterior de sociedades cooperativas andaluza, señala: "En efecto, el artículo 94.5 de la L.S.C.A., en relación con el artículo 5, establece un límite de responsabilidad del socio, pero en cuanto a las deudas de la Cooperativa con terceros, no en cuanto a las relaciones internas de la sociedad y el socio. En consecuencia, a las pérdidas derivadas de operaciones de los socios con su propia Cooperativa, de deudas de éste con la sociedad, no le es de aplicación el límite establecido en el artículo 5 L.S.C.A. sobre la responsabilidad del socio hasta su aportación al capital. A esta conclusión le añade el Juzgador de instancia hasta cinco razones, que esta Sala desde luego comparte en su integridad, habiéndose pronunciado también al respecto en la sentencia $n^{\circ} 164$, Rollo de Apelación no 247/09, en la que se incide en el principio de solidaridad que debe presidir el sistema cooperativista, tal y como recoge el Juzgador a quo en la sentencia aquí apelada”.

Esta posición fue seguida también por la Sentencia de la Audiencia Provincial de Navarra de 5 de septiembre de $2018^{33}$, en la que, con numerosas citas a la doctrina mayoritaria ${ }^{34} \mathrm{y}$ tras fundamentar su decisión en diferentes preceptos de la Ley Foral navarra, se concluye: "Resulta acorde con la lógica la razón de ser y esencia de la sociedad cooperativa que y como se ha visto al igual que los socios cooperativistas participan de los resultados positivos de la actividad, también, lo sean y en la misma medida

32. ACl2012\555; en la senda de un pronunciamiento anterior de 13 de julio de 2010, JUR\2010\369748.

33. TOL6.955.812.

34. El fragmento que recoge la opinión doctrinal mayoritaria es del siguiente tenor: "La doctrina mayoritaria considera que el régimen de responsabilidad del socio cooperativista por las pérdidas no es de limitación al importe de las aportaciones al capital social, sino de carácter ilimitado ("En el análisis de esta problemática responsabilidad del socio la mayoría de la doctrina cooperativa sigue la estela de la conocida opinión de Vicent Chuliá (v., críticamente, Paniagua Zurera [1997, 306 ss. y 423 ss.; 2005, 87 ss. y 288 ss.], Gomeza Villa [2001, 296 ss.] y Gadea/Sacristán/Vargas [2009, 505 ss.]), quien distinguía ya con ocasión de la derogada Ley General de Cooperativas 3/1987 (1994, 192 ss.) entre dos tipos de responsabilidad, "ad extra" y "ad intra", haciéndose eco de una anterior construcción de Paz Canalejo $(1979,197)$ y asimismo de Fajardo García (v. expuesta en su tesis de 1992 y, posteriormente en parte ya publicada [1997, 197 ss.]). En este sentido, se habla de la "responsabilidad "ad extra" del socio cooperativista" para referirse a su parte o suma de responsabilidad por las deudas sociales que la cooperativa tiene contraídas con sus propios acreedores ...[...].... Mientras que se habla también de una "responsabilidad "ad intra" del socio cooperativista" para poner el punto de mira en la sociedad cooperativa, para aludir a una responsabilidad del socio en relación con su propia entidad y en virtud de las relaciones jurídicas contraídas con ésta; una responsabilidad que, a diferencia de aquella "ad extra", se predicaría ya de carácter ilimitado, pues se afirma que la suma de responsabilidad del socio alcanzaría a la totalidad de su patrimonio personal (o, en palabras de Vicent Chuliá, "como característica más de la cooperativa, sus socios responden ilimitadamente con todo su patrimonio de la gestión de sus intereses que confían a la cooperativa ["masa de gestión de la cooperativa"], asumiendo un riesgo propio, ...”; referencia recogida por el Profesor Martínez Segovia en el comentario a la STSJM de no 573/13, de 11 de septiembre, en la que se estima tal es el caso de socio de una sociedad cooperativa de trabajo asociado)". 
las pérdidas que resulten de aquella, sin perjuicio de las posibles acciones frente a los órganos de gestión, lo que se adecua a la naturaleza de la sociedad de satisfacer las necesidades o aspiraciones económicas y sociales de sus socios, como es en este caso el poder desarrollar un trabajo que es organizado por la cooperativa no siendo el resultado sino el del conjunto del trabajo de los socios. En definitiva, en el supuesto de autos, consideramos que el régimen de responsabilidad de los socios cooperativistas, aun habiendo causado baja, es de responsabilidad ilimitada respecto de las pérdidas de la sociedad en los ejercicios en que hubiera sido socios cooperativistas (la cursiva es nuestra)". Sin embargo, esta sentencia ha sido anulada -en mi modesta opinión- de forma sorprendente dada su robusta argumentación, por el Tribunal Superior de Justicia de Navarra en Sentencia de 2 de julio de $2019^{35}$, que limita la imputación de pérdidas a los socios al importe de sus aportaciones a la cooperativa, pese a que la legislación navarra no contiene dicha previsión, apoyándose en la Sentencia del Tribunal de Justicia de Cataluña de 6 de noviembre de $2014^{36}$. Se considera que en las modernas legislaciones, como hace la Ley de Cooperativas de Cantabria en su artículo 72.2 in fine o la Ley de Sociedades Cooperativas Andaluzas en su artículo 69.2 in fine, se tiende a limitar la responsabilidad de los cooperativistas no solo en relación con las deudas sociales sino también con la imputación de pérdidas, en aras de fomentar el desarrollo de estas formas societarias. Mucho más acertado, y coherente con la legislación navarra considero el voto particular del magistrado Fernández Urzainqui, que en la línea de lo aquí mantenido entiende que no puede limitarse la imputación de pérdidas a falta de un precepto legal que explícitamente así lo prevea y que dicha limitación jurisprudencial puede comprometer la solvencia y el equilibrio o la estabilidad patrimonial de estas sociedades. Otra cuestión es que de lege ferenda pueda debatirse. Dicho debate debe partir, en todo caso, del mantenimiento de la responsabilidad de los socios por sus deudas con la cooperativa derivadas de la producción de bienes y de la prestación de servicios cooperativizados ${ }^{37}$, que debe ser ilimitada tal y como afirma en el artículo 4.3 de la Ley de Cooperativas de la Comunitat Valenciana ${ }^{38}$.

\section{ECLI:ES:TSJNA:2019:412.}

36. ECLI:ES:TSJCAT:2014:12006. Véase también: STSJ Cataluña (Barcelona/Civil-Penal/Secc. 1) de 9-22006, ECLI:ES:TSJCAT:2006:1630; STSJ Cataluña, de 31-2-2011, ECLI:ES:TSJCAT:2011:2688; STSJ Cataluña de 18-9-2014, ECLI:ES:TSJCAT:9925, citadas por ALFONSO SÁNCHEZ, R.: "Régimen...", p. 506; quien en las páginas anteriores comenta estas sentencias en relación con la STSJ de Navarra de 2 de julio de 2019.

37. Vid. VARGAS VASSEROT, C., GADEA SOLER, E. \& SACRISTÁN BERGIA, F., op. cit., p. 184; destacan el carácter diferenciado de esta cuestión.

38. Esta responsabilidad puede limitarse en los estatutos de conformidad con el artículo 69.3 LCCV: "Si los estatutos sociales lo establecen, las pérdidas derivadas de la actividad cooperativizada con las personas socias 
Muy clara respecto de la diferencia entre responsabilidad por deudas sociales de la cooperativa e imputación de pérdidas es la legislación extremeña. En un mismo precepto se ocupa de ambos supuestos. La responsabilidad del socio por las deudas sociales, salvo disposición en contrario fijada en los estatutos, estará limitada a las aportaciones suscritas al capital social, estén o no desembolsadas (art. 76.1 LSCEx). De este modo, cuando el socio cause baja en la sociedad cooperativa responderá personalmente de las obligaciones contraídas con terceros por la sociedad cooperativa con anterioridad a su baja, hasta el importe reembolsado de sus aportaciones al capital social, previa excusión del haber social, y durante cinco años desde la pérdida de su condición de socio (art. 76.2 LSCEx). Distinta de esta responsabilidad externa, es la que se deriva en el ámbito interno, en el que el socio responderá del cumplimiento de los contratos y obligaciones asumidos con la sociedad cooperativa, que pueden derivarse de acuerdos cooperativos no impugnados por el socio, y alcanza a pérdidas ya imputadas o pendientes de imputación, como podría ser el caso de deuda bancaria todavía no vencida. Así, en la normativa extremeña se establece: "El socio que cause baja en la sociedad cooperativa o que sea expulsado seguirá obligado al cumplimiento de los contratos y otras obligaciones que haya asumido con la sociedad cooperativa, que por su naturaleza no se extingan con la pérdida de la condición de socio. Los acuerdos aprobados por la asamblea general que impliquen inversiones, ampliación de actividades o planes de financiación en los que se haya individualizado la obligación que corresponde a cada socio, o los acuerdos por los que se exijan al socio nuevas aportaciones obligatorias, cuando no hayan sido recurridos en tiempo y forma por el socio, darán lugar, si se produce su baja o su expulsión, a que responda personalmente de las obligaciones que le correspondan por tales acuerdos en los términos que se determine por la sociedad cooperativa en la liquidación de las aportaciones. El socio que cause baja o que sea expulsado estará obligado a pagar las pérdidas que se le hayan imputado y las que estén pendientes de imputación por cualquier motivo. La liquidación de las obligaciones económicas asumidas por el socio con anterioridad a su baja o expulsión se practicará conforme a lo establecido en el artículo 73 de esta Ley”. En resumen, en el párrafo 3 del artículo 76 de la Ley de sociedades cooperativa de Extremadura se recoge la responsabilidad del socio por obligaciones y contratos que haya asumido con la cooperativa o por imputación de pérdidas o derramas aprobadas por la asamblea general, sin limitación cuantitativa a las aportaciones realizadas

que se imputen a estas, alcanzarán como máximo el importe total de los anticipos asignados a las personas socias en el ejercicio económico, más sus aportaciones a capital social y su participación en las reservas repartibles". 
o al importe reembolsado por el capital, que es la regla de los números 1 y 2 para el caso de responsabilidad por las deudas sociales ${ }^{39}$.

Interesa destacar que no es nada extrańo a nuestras leyes de cooperativas la imputación de inversiones realizadas y no amortizadas o de pérdidas que no se habían imputado. Así en legislación catalana, se permite que los estatutos establezcan "que, en caso de baja, los socios respondan ante la cooperativa, durante el plazo que establezcan los propios estatutos, que nunca puede ser superior a cinco ańos, de las inversiones realizadas y no amortizadas, en proporción a su actividad cooperativizada de los últimos cinco años o, en su caso, del plazo fijado a estos efectos por los estatutos o por el reglamento de régimen interno" [art. 19.6 $\mathrm{LCCat}^{40}$; la vigente Ley de cooperativas castellano-manchega, también permite en su artículo 82.2 a) imputar las deudas por inversiones realizadas y que estén pendiente de pago ${ }^{41}$.

39. Vid., sin embargo, la STSJ de Cataluña de 6 de noviembre de 2014 (TOL4.697.832) en la que pese a reconocer esta diferenciación y el carácter ilimitado de la imputación de pérdidas, salvo que la legislación cooperativa concreta señale lo contrario, como hace la legislación catalana aplicada en la sentencia para los socios que permanecen en la cooperativa, acaba aplicando la misma regla para el socio que causa baja. Y ello con una referencia a que la doctrina moderna se pronuncia a favor de la limitación de la imputación de pérdidas a las aportaciones realizadas o comprometidas en aras de una mayor implantación de la forma societaria cooperativa, así como por una equivocada -a mi entender, como más adelante se mantiene en este artículo- necesidad de igualdad de trato del socio que permanece en la cooperativa y del socio que causa baja. Cuestión distinta es que de lege ferenda convenga aproximar el régimen legal del socio al de las sociedades de capital, lo que no es una cuestión tan fácil de dilucidar si se piensa en la situación económica y el interés de la cooperativa y, por ende, de los socios que continúan en la cooperativa.

40. Aspecto este destacado por PULGAR EZQUERRA, J.: "La pérdida de la condición de socio en el marco cooperativo: su baja y expulsión". En: Estudios de Derecho Mercantil en memoria del Profesor Aníbal Sánchez Andrés (coords. SÁENZ GARCÍA DE ALBIZU, J.C., OLEO BANET, F. \& MARTÍNEZ FLOREZ A.), Editorial Civitas, Cizur Menor, 2010, p. 1079.

41. El tenor literal del art. 82.2 a) LCCM es el siguiente (la cursiva es nuestra): "En todo caso, la liquidación del importe efectivo a reembolsar de las participaciones sociales se practicará a partir del balance de cierre del ejercicio social en el que se ha originado el derecho al reembolso, conforme a las normas siguientes: a) Del valor acreditado de las participaciones suscritas por el socio, se podrán efectuar las siguientes deducciones y descuentos: En los supuestos que corresponda, se deducirán, en primer lugar, las pérdidas imputadas o imputables al socio, reflejadas en el balance de cierre del ejercicio en el que se produzca la pérdida de tal condición, ya correspondan a dicho ejercicio o provengan de otros anteriores y estén sin compensar y, en segundo lugar, las sanciones económicas impuestas al socio que no hubieran sido satisfechas. (...) Se deducirán aquellas obligaciones de pago que el socio tenga pendientes con la cooperativa derivadas de su participación en la actividad cooperativizada, asi como la parte proporcional que, de acuerdo a la actividad cooperativizada realizada por el socio, le corresponda de las deudas de la sociedad vinculadas a inversiones realizadas y que estén pendientes de pago, asi como aquellas otras obligaciones por cualquier otro concepto.

En los casos de baja no justificada, se podrá establecer una deducción de las participaciones obligatorias que no podrá superar el veinte por ciento, mientras que en caso de exclusión esa deducción podrá alcanzar hasta el treinta por ciento. 


\section{Responsabilidad de los socios de una sección e imputación de pérdidas}

La sección de una cooperativa ha sido definida como una "demarcación autónoma funcional... que no llega a adquirir personalidad jurídica propia o independiente de la de la cooperativa, pero que es gestionada separadamente y en cuyo ámbito pueden concretarse responsabilidades con referencia a un patrimonio delimitado al efecto, excluyendo así al resto del patrimonio de la sociedad" ${ }^{2}$. De esta definición conviene destacar que la sección tiene autonomía funcional, sin llegar a adquirir personalidad jurídica ${ }^{43}$. Por tanto, no existe un sujeto, una persona jurídica, además de la cooperativa, titular de derechos y obligaciones. Cuestión distinta es si, al carecer de personalidad jurídica, las secciones tienen un patrimonio separado, distinto de la cooperativa, al que puedan o deban dirigirse los terceros, lo que ocurre en las secciones de las cooperativas de viviendas, tal y como establece, por ejemplo, el artículo 12.3 de la Ley 14/2011, de 23 de diciembre, de Sociedades Cooperativas Andaluzas. En todo caso, el patrimonio de las secciones puede configurarse en los estatutos y en los contratos con terceros puede limitarse la responsabilidad por las deudas sociales a dicho patrimonio. Y a efectos internos, dada la autonomía de gestión, lo propio es que las pérdidas y los compromisos adquiridos con terceros por las actividades específicas de las secciones se imputen al patrimonio configurado separadamente de la sección y a falta de este a sus socios. Y así es cómo debiera configurarse en los estatutos de las sociedades cooperativas para evitar cualquier duda interpretativa al efecto y evitar conflictos entre los socios de la sección y la sociedad.

Como ya seńaló la profesora FAJARDO: "La sección puede tener un patrimonio propio afecto a la actividad que desarrolla, y que se formará principalmente con aportaciones a capital social de los socios de la sección, con los excedentes no distribuidos y beneficios obtenido en el desarrollo de esta actividad, y las cuotas de ingreso y periódicas que se exijan a los socios" ${ }^{44}$. Este patrimonio no es, como se ha avanzado, un patrimonio independiente del patrimonio de la cooperativa, pero por razones funcionales se destina parte del patrimonio al desarrollo de una determinada actividad que es el objeto de la sección. Las leyes de cooperativas suelen hacer una prelación de los bienes que garantizan la responsabilidad de la cooperativa por las deudas procedentes de actividades desarrolladas bajo una sección. Por estas deudas responderán,

42. Vid. SANTOS MARTÍNEZ, V.: "Las secciones de las cooperativas en el Derecho español", Revista Juridica de Catalunya (RJC), no 79(4), 1980, p. 967.

43. Vid., sin embargo, MUÑOZ VIDAL, A.: "Secciones de Cooperativas: su personalidad jurídica”, Mundo Cooperativo, no 699-700, 1978, p. 9; quien considera que la secciones tienen personalidad jurídica; ap. DOMÍNGUEZ CABRERA, M.P., op. cit., p. 58.

44. Vid. FAJARDO GARCÍA, I.G., La gestión..., pp. 207 y ss. 
en primer lugar, el patrimonio de la sección y, posteriormente, el resto de bienes de la cooperativa. En esta línea se pronuncian diversas leyes autonómicas (ad. ex.: art. 9.6 Ley 6/2013, de 6 de noviembre, de Cooperativas de Cantabria; art. 6.2 Ley 4/2002, de 11 de abril, de Cooperativas de la Comunidad de Castilla y León; art. 6.3 LCAR; art. 12.1 LSCAnd ${ }^{45}$ ) y el artículo 5.2 de la Ley 27/1999, de 16 de julio, estatal de Cooperativas, que señala: "Del cumplimiento de las obligaciones derivadas de la actividad de la sección responden, en primer lugar, las aportaciones hechas o prometidas y las garantías presentadas por los socios integrados en la sección, sin perjuicio de la responsabilidad patrimonial universal de la cooperativa" ${ }^{36}$.

Sin embargo, pese a la dicción literal de los preceptos citados, debe hacerse una interpretación de dichas normas que parta de que el único centro de imputación de responsabilidad por las deudas sociales con terceros es la cooperativa, que deberá satisfacer la misma primero con los bienes de la sección y después con otros bienes de la cooperativa, y si lo hace con estos mismos podrá repetir, como prevé la Ley aragonesa o andaluza contra los socios de la sección. Al tercero que reclame le es indiferente los bienes con los que la cooperativa satisfaga su pretensión. Y esta interpretación es acorde con el control que los órganos de la cooperativa -la asamblea o el órgano de administración, según la ley aplicable- ejercen sobre los acuerdos adoptados por los órganos decisorios de la sección, en concreto con la facultad de suspender estos últimos. En mi opinión, se trata de normas que establecen una prelación a efectos internos, entre los socios de la sección y la cooperativa, de modo que como se recoge expresamente en algunas leyes cooperativas, para que la subordinación o subsidiariedad de la responsabilidad de la sociedad cooperativa tenga alguna relevancia frente a terceros es imprescindible que así se haga constar en los contratos celebrados con los terceros. Sin el compromiso contractual previo de los terceros, no se les podrá impedir que persigan directa o indirectamente los bienes de la cooperativa, aunque queden bienes afectos a la sección. La obligatoriedad de esta prelación deriva, por tanto, del consentimiento expreso de las partes, y no de la estructura económica y jurídica de la cooperativa ${ }^{47}$.

45. Vid. MORILLAS JARILLO, M.J.: op. cit., p. 88; señala que el art. 12.1 LSCAnd establece una graduación de la responsabilidad de la sección y de la cooperativa, de modo que el patrimonio de la sección responderá en primer lugar de las deudas de la sección y en segundo el patrimonio de la cooperativa. Destaca, sin embargo, que el art. 12.3 LSCAnd, parece predicar la independencia patrimonial solo de las secciones de las cooperativas de viviendas.

46. Interpretando que este artículo establece también una graduación de la responsabilidad de la sección y de la cooperativa por las deudas de la sección, es de obligada referencia el trabajo de GADEA SOLER, E., op. cit., pp. 613 y ss. Véase también en este sentido: DOMÍNGUEZ CABRERA, M.P., op. cit., pp. 68 y ss.

47. El tenor literal del art. 7 de la Ley 1/2003, de 20 de marzo, de Cooperativas de las Illes Balears es el siguiente: "La afectación del patrimonio de las secciones a los resultados de las operaciones que en su seno se 
Esta adecuada comprensión de la responsabilidad de las secciones por las deudas sociales se recoge expresamente en el artículo 14.2 de la Ley 9/2018, de 30 de octubre, de sociedades cooperativas de Extremadura. Esta Ley, pese a reconocer explícitamente que las cooperativas pueden tener un patrimonio separado de la sección, y establecer el mencionado orden de prelación, exige que el régimen de responsabilidad para su aplicación debe hacerse constar en los contratos que se celebren con los terceros. Estos son los términos del precepto mencionado: "No obstante, los estatutos sociales, al regular la sección, podrán prever que además tenga patrimonio separado. En este caso, del cumplimiento de las obligaciones derivadas de la actividad de la sección responderán, en primer lugar, los bienes adquiridos con cargo a la sección, las aportaciones hechas o prometidas y las garantías presentadas por los socios integrados en la sección. Dicho régimen de responsabilidad deberá hacerse constar en los contratos que se celebren con los terceros". Y se ańade en el segundo párrafo del artículo 14.2 LSCEx: "En todo caso, persistirá la responsabilidad patrimonial universal de la sociedad cooperativa, con excusión del patrimonio de la sección afectada y con atención a las disposiciones que regulan la constitución por fases o promociones respecto de las sociedades cooperativas de viviendas". La necesidad de que contractualmente los terceros se obliguen con la cooperativa a satisfacer sus créditos, en primer lugar, con los bienes de la sección, se exige también en la Ley 11/2010, de 4 de noviembre, de Cooperativas de Castilla-La Mancha, cuyo artículo 9.5 requiere hacer constar dicha responsabilidad, por delante de otros bienes de la cooperativa, en los contratos con los terceros a pesar de que la norma legal expresamente exige también que "la afectación preferente del patrimonio de las secciones a las resultas de las operaciones que en su seno se realicen habrá de ser inscrita en la Unidad correspondiente del Registro de Cooperativas de Castilla-La Mancha para su oponibilidad a terceros" (véase también art. 7.3 LCIB) ${ }^{48}$. Los términos de la Ley valenciana también son muy claros en la exigencia de dicho contrato: "Del cumplimiento de las obligaciones de-

realicen, deberá ser inscrita en el registro de cooperativas de las Illes Balears que se establece en el artículo 16 de esta ley, sin perjuicio de que conste expresamente en el texto de los contratos correspondientes. En todo caso, persistirá la responsabilidad patrimonial universal de la cooperativa, con exclusión (sic) del patrimonio de la sección afectada y con atención a las disposiciones que regulan la constitución por fases o promociones respecto de las cooperativas de viviendas".

48. En la misma línea, el tenor literal del art. 7.3 de la Ley 1/2003, de 20 de marzo, de Cooperativas de las Illes Balears es el siguiente: "La afectación del patrimonio de las secciones a los resultados de las operaciones que en su seno se realicen, deberá ser inscrita en el registro de cooperativas de las Illes Balears que se establece en el artículo 16 de esta ley, sin perjuicio de que conste expresamente en el texto de los contratos correspondientes. En todo caso, persistirá la responsabilidad patrimonial universal de la cooperativa, con exclusión del patrimonio de la sección afectada y con atención a las disposiciones que regulan la constitución por fases o promociones respecto de las cooperativas de viviendas". 
rivadas de la actividad de la sección responderán, en primer lugar, las aportaciones hechas o prometidas y las garantías prestadas por quienes integran la sección. Esta condición constará necesariamente en los contratos celebrados con terceras personas, consintiendo estas en no perseguir directa o inmediatamente los demás bienes de la cooperativa, bajo la responsabilidad de los que hayan contratado en representación de la cooperativa" (art. 8.6 LCCV).

Con mayor o menor dificultad hermenéutica en unas leyes autonómicas respecto de otras, de su análisis y sin ánimo de ser exhaustivo, puede concluirse que a efectos externos la limitación de responsabilidad de la cooperativa a los bienes de la sección o, mejor dicho, la excusión de los bienes de la sección antes de verse afectados el resto de los bienes de la cooperativa, requiere que ello se haya pactado contractualmente con el acreedor. Por otra parte, dada la autonomía de gestión y la existencia de un cierto patrimonio separado de la sección, si finalmente son los bienes de la cooperativa distintos de los de la sección los que quedan afectados por sus deudas, por insuficiencia o falta de ellos o por cualquier otro motivo, la cooperativa podrá repetir frente a los socios de la sección, así como imputar pérdidas a sus socios.

De no hacerse constar el orden de prelación de la responsabilidad por deudas en los contratos con terceros, los preceptos que regulan este aspecto deben interpretarse en el sentido de que establecen una ordenación de las responsabilidades que asume el patrimonio de la cooperativa con relevancia a efectos internos, pues lo que se pretende es que el patrimonio diferenciado garantice las obligaciones de la cooperativa contraídas en interés de la sección y que, por otra parte, el patrimonio de la sección no se vea perjudicado por las pretensiones de los acreedores por créditos con origen en las actividades distintas de la sección. La autonomía funcional y de gestión de las secciones, con la facultad de la cooperativa de llevar políticas económicas separadas (porcentaje de distribución de excedente, intereses de capital, precios de las operaciones), así como la obligación que imponen las leyes cooperativas de llevar una contabilidad separada y de someter las cuentas de la cooperativa a auditoría (ad. ex. Art. 14.1 y 5 LSCEx o art. 6.1 y 6 LCEus), llevan a entender el orden de prelación de responsabilidad, a falta de su imposición en los contratos con terceros, en el orden estrictamente interno con efectos en dos sentidos: por una parte, impone una prelación a la hora de elegir los bienes con los que la cooperativa hará frente a las reclamaciones de los acreedores, siendo lo lógico que las reclamaciones de las actividades específicas de la sección se satisfagan con los bienes que integren el patrimonio separado de la sección; por otra parte, de utilizar la cooperativa bienes distintos de la sección para el cumplimiento de obligaciones con origen en sus actividad, principalmente a falta de bienes de la sección, podrá repetir contra los socios de la sección para resarcirse de las cantidades desembolsadas por el cumplimiento de las responsabilidades derivadas de actividades 
específicas de la sección (una referencia a la facultad de repetición se contiene, por ejemplo, en el art. 7 LCCV, art. 6.3 LCAr, art. 9.5 LCCLM o art. 6.4 LCCat).

A falta de previsión legal, conviene fijar estatutariamente las reglas que permitan, tanto mantener indemne el patrimonio de la cooperativa como, viceversa, proteger el patrimonio de la sección derivado principalmente de las cuotas y aportaciones de los socios adscritos y de los resultados de la actividad objeto de la sección, toda vez que la autonomía funcional de la sección no debe perjudicar el patrimonio de los socios que no pertenecen a la misma, ni el patrimonio de la sección debe ser perjudicado por la actividad de la cooperativa. Para proteger el patrimonio de la cooperativa y la actividad cooperativizada distinta de la que tiene por objeto la sección, pero también el patrimonio y la actividad de esta, las leyes cooperativas establecen que por acuerdo de la asamblea general se podrá acordar la suspensión inmediata de la junta de personas socias de una sección (ad. ex. arts. 6.5 LCEus, 14.3 LSCEx o art. 9.3 LCCLM que legitima también al órgano de administración $\left.{ }^{49}\right)$.

Ahora bien, pueden surgir dudas en cuanto al alcance de la facultad de repetición que tiene la cooperativa contra los socios de la sección. Veamos el texto, por ejemplo, de la Ley de Cooperativas de Castilla-La Mancha: "En todo caso, si la cooperativa tuviere que hacer frente a las responsabilidades contractuales o extracontractuales derivadas de la actuación de una sección, podrá repetir contra los socios integrados en ella, exigiendo el efectivo desembolso del valor nominal de las participaciones suscritas o las garantías prestadas por los socios integrados en la sección" (art. 9.5 LCCLM). Enseguida surge la duda de si la facultad de repetición alcanza todo el patrimonio de los socios integrados en la sección o viene limitada a los desembolsos pendientes del valor nominal de las participaciones suscritas o las garantías prestadas por los socios. En mi opinión, al tratarse de una regla de régimen interno de la cooperativa, que no viene afectada por la limitación de responsabilidad frente a terceros a los desembolsos realizados o comprometidos por los socios, la referencia a la exigencia del efectivo desembolso de las participaciones o a las garantías otorgadas no puede entenderse como una mención taxativa o una limitación del objeto de la facultad de repetición de la cooperativa sino como ejemplos del objeto de dicha facultad de repe-

49. La legislación de Castilla-La Mancha tiene algo más de detalle al prever el procedimiento para determinar la nulidad definitiva del acuerdo de la sección: "El órgano de administración y, en su caso, la asamblea general de la cooperativa, podrá acordar la suspensión cautelar con efectos inmediatos de los acuerdos adoptados por la asamblea de sección, debiendo hacer constar los motivos por los que los considera contrarios a la Ley, a los estatutos sociales o al interés general de la cooperativa. En todo caso, el órgano de administración convocará la asamblea general en el plazo máximo de 30 días, a contar desde la fecha del acuerdo de suspensión, a fin de que ésta ratifique, modifique o anule definitivamente el acuerdo de la Sección. Transcurrido dicho plazo sin que se haya convocado la asamblea, se considerará ratificado el acuerdo de la asamblea de Sección, sin perjuicio de lo dispuesto en el artículo 54 para la impugnación de acuerdos sociales" (art. 9.3, segundo párrafo LCCLM). 
tición que alcanzaría a todos los bienes que integren el patrimonio de los socios de la sección. Esta interpretación se impone en tanto refuerza la autonomía de gestión de las secciones, la necesidad de que su actuación no perjudique a los socios de la cooperativa que no formen parte de ellas, y la asunción por los socios de la responsabilidad por las operaciones específicas de cada una de las secciones, lo que es compatible con el mantenimiento de la responsabilidad general y unitaria de la cooperativa, esto es, con la responsabilidad patrimonial de la cooperativa frente a terceros.

En cualquier caso, para eliminar cualquier atisbo de duda interpretativa, conviene que los estatutos de las cooperativas ${ }^{50}$, entre las reglas de funcionamiento de la sección, establezcan claramente que la actividad de la sección no podrá perjudicar el patrimonio y los intereses generales de la cooperativa, ni a los socios que no formen parte de la sección, debiendo recaer todas las obligaciones económicas y sus consecuencias sobre los bienes y patrimonio de la sección correspondiente y sobre el patrimonio de sus miembros, de modo que la cooperativa podrá repetir contra los socios de la sección la responsabilidad que hubiere asumido en orden al cumplimiento de los compromisos adquiridos con terceros. Además, es conveniente fijar si la responsabilidad de los socios de la sección es subsidiaria de la de la sección con su patrimonio, esto es, previa excusión del patrimonio de la sección- o, por el contrario, no se requiere de insolvencia previa de la sección para derivar responsabilidad a sus socios.

Por otra parte, también resultaría aclaratorio fijar en los estatutos, una regla que a mi modo de ver está implícita en la regulación cooperativa: que la exigencia por la cooperativa a los socios de la sección de sus responsabilidades por las obligaciones asumidas no está condicionada al previo pago por la cooperativa de dichas obligaciones con terceros.

Estas reglas estatutarias de funcionamiento y de reparto de responsabilidad no aminoran el patrimonio de la cooperativa afecto a su responsabilidad patrimonial, por lo que resultan totalmente compatibles con la legislación vigente. No existe en el plano de los principios ningún obstáculo a que la limitación o exclusión de responsabilidad de los socios frente a terceros coexista con la responsabilidad ilimitada de los socios frente a la cooperativa por dichas deudas o por pérdidas. Es más, la fijación estatutaria de estas reglas tendría efectos meramente aclaratorios puesto que las mismas derivan de una interpretación teleológica de las escasas normas legales sobre las secciones cooperativas.

50. Las distintas leyes sobre cooperativas otorgan suficiente libertad para configurar estatutariamente el funcionamiento de la sección y la responsabilidad de sus socios, como es de ver en el art. 6.1 LCAr: "Los estatutos de la cooperativa podrán establecer y regular la existencia, organización y funcionamiento de secciones que desarrollen actividades económicas o sociales específicas dentro de su objeto social, con autonomía de gestión, sin perjuicio de la responsabilidad general y unitaria de la cooperativa". 


\section{Imputación de pérdidas y obligaciones no vencidas al causar baja el socio de una sección}

Una cuestión no resuelta, al menos explícitamente, por la mayoría de leyes cooperativas es la imputación al socio de una sección que ha causado baja de obligaciones no vencidas o de los costes de financiación de inversiones por deuda bancaria.

En general, las leyes cooperativas regulan la responsabilidad de los socios por las deudas sociales frente a terceros tras su baja de la cooperativa y ello es objeto de previsión en los estatutos de las sociedades cooperativas. Por lo general, las leyes coinciden en configurar dicha responsabilidad de los socios como limitada, tanto desde un punto de vista temporal (5 años) y cuantitativo (importe reembolsado de sus aportaciones al capital social), como objetivo (deudas contraídas por la Cooperativa con anterioridad a la baja) y de carácter subsidiario (previa excusión del haber social).

Como se ha explicado supra, la responsabilidad limitada, que asume el socio -también el que causa baja- se diferencia claramente de la imputación de pérdidas de la cooperativa a los socios para la que no existen límites cuantitativos, ni se exige la insolvencia de la sociedad cooperativa ni la previa excusión del patrimonio de la cooperativa o el previo pago de la obligación. Efectivamente la responsabilidad de los socios frente a la cooperativa no se limita en ningún precepto al importe reembolsado al socio que causa baja.

De ahí que en la materia los órganos de la cooperativa deban imputar las pérdidas y las obligaciones por compromisos adquiridos con terceros derivadas de actividades específicas de la sección a los bienes y patrimonio de esta o de sus miembros, toda vez que rige en todas sus consecuencias el principio de que las decisiones de la sección no podrán perjudicar el patrimonio e intereses generales de la cooperativa ni los de sus socios. La responsabilidad universal de los miembros de una sección por los compromisos adquiridos con terceros por su actividad específica puede exigirse por la cooperativa en cualquier momento mientras pertenezcan a la sección, en el momento en que comuniquen su baja o, incluso, después una vez producida la baja. Esta interpretación es coherente con la no aplicación en la esfera de responsabilidad interna del límite del importe reembolsado por sus aportaciones al capital social, lo que permite a la cooperativa reclamar al socio que ha causado baja su responsabilidad por pérdidas e inversiones. De lo contrario, mientras los socios que siguen en la sección y en la cooperativa continúan siendo responsables de las obligaciones contraídas con terceros, los socios que causaren baja dejarían de asumir dicha responsabilidad. Por ello, no solo debe considerarse como una facultad sino más bien como una obligación de la cooperativa reclamar al socio que deja la sección, en el momento de la baja, o posteriormente, su parte de pérdidas o deudas con terceros, conforme le corresponda 
por su actividad cooperativizada sobre el neto patrimonial de la sección. En esta línea es muy clarificadora la previsión de la legislación vasca en materia de responsabilidad en la que, tras dejar claro que los socios no responden por la deudas sociales, señala: "Las personas socias que hubieran, expresa y específicamente, suscrito contratos o asumido obligaciones con la sociedad cooperativa y que, por su naturaleza, no se extinguen con la pérdida de la condición de persona socia responderán de su cumplimiento aún después de causar baja" (art. 59.4 LCEus). Si puede afirmarse que los socios de la sección quedan comprometidos frente a la cooperativa a responder de las obligaciones con terceros por la actividad separada de la sección, se les puede imputar dichas pérdidas o deudas.

Como se ha dicho, el ejercicio de la facultad de la cooperativa de solicitar a los socios de una sección el cumplimiento de sus obligaciones no se subordina a la existencia de pérdidas. Sin embargo, en tanto será habitual que se requiera el cumplimiento de sus obligaciones en caso de pérdidas cooperativas, debe tenerse en cuenta las previsiones estatutarias al efecto, que pueden imponer compensar primeramente una parte de la pérdidas a fondos de reserva voluntarios o, incluso, al fondo de reserva obligatorio (a estas normas estatutarias se remiten las leyes de cooperativas, que limitan el porcentaje de la deuda que puede imputarse al fondo obligatorio (véanse, por ejemplo, arts. 73.1 LCEus, 58.5 LCAr, 69.1 LCCV).

En este contexto, respecto de las reglas vascas de imputación de pérdidas, la sentencia de la Audiencia Provincial de Guipúzcoa (sección 2a), de 27 de marzo de $2013^{51}$, ha señalado que "(l) a imputación de pérdidas al socio se configura con carácter de excepcionalidad dentro del régimen cooperativo, de ahí que sea necesario acudir a criterios de interpretación restrictiva a la hora de determinar si se han cumplido o no los requisitos de exigibilidad para dicha imputación de pérdidas tanto a la hora de acreditar las deudas como en la comunicación de las mismas a los socios que causaron baja”. Este criterio de excepcionalidad o de interpretación restrictiva para la imputación de pérdidas no puede, sin embargo, aplicarse para evitar que los socios de las secciones, incluidos los que se han dado de baja, dejen de asumir sus responsabilidades derivadas de actividades específicas. Por eso, la exigencia de no imputar deudas a los socios será mutatis mutandi aplicable a los socios de la sección únicamente para el caso de que en dichos fondos queden bienes obtenidos por la actividad de la sección. La determinación de dichos bienes, esto es, la acreditación de existencia de dichos bienes obtenidos por la actividad de la sección será posible de haberse llevado, como exigen las normas y los estatutos de las cooperativas, una contabilidad separada. Incluso respecto de los socios ajenos a la sección, debe distinguirse entre el 
supuesto de imputación de pérdidas y el de exigencia de responsabilidades y compromisos que haya asumido el socio, por ejemplo, en materia de inversiones. Nada ha de impedir que, pese a la existencia de resultados positivos en la cooperativa, pueda exigirse al socio que causa baja su responsabilidad con la cooperativa por determinadas obligaciones o inversiones y, por supuesto, ello ha de poder realizarse respecto de socio de una sección por las pérdidas en que incurra esta.

En cuanto a las pérdidas o deudas imputables, se ha señalado por nuestros tribunales que no ha de hacerse distinción por la naturaleza de las deudas de la cooperativa, o de la sección, que se pretendan imputar a los socios y, por tanto, nada impide que la deuda imputable sea bancaria. Así, en la Sentencia del Tribunal Supremo (Sala de lo Civil) de 13 de marzo de $1987^{52}$, vigente la Ley de Cooperativas estatal de 1974 , se atribuyen al socio las deudas bancarias "en la cuantía fijada que comprende no solo los costes financieros de las operaciones de crédito, sino también la parte correspondiente de las obligaciones contraídas, cuantía... «sobre cuyo cálculo matemático y financiero referente a porcentajes de repercusión, importe de amortización e intereses a lo largo de esos cinco años», como dice la sentencia recurrida, «ni siquiera se ha formulado objeción alguna», así como tampoco se ha combatido en este recurso si bien, como se desprende del citado artículo 11, la responsabilidad de Ebro deberá hacerse efectiva, como expresa la sentencia de primera instancia-confirmada en apelación- en ejecución de Sentencia, debiendo entenderse que en la cuantía expresada y en los plazos que le hubieran correspondido de haber permanecido como socio de la cooperativa, pues su responsabilidad no puede resultar agravada por haber causado baja en ella".

Otro caso de imputación de deuda bancaria a los socios dados de baja de una cooperativa se ilustra en la Sentencia de la Audiencia Provincial de Jaén (Sección 1a) de 13 de julio de $2010^{53}$, en la que se imputa deuda proveniente de la financiación de los préstamos o créditos que la cooperativa tiene con entidades bancarias, considerándose que se trata de una pérdida que ya se ha producido, de una deuda líquida que, por tanto, es imputable a los socios que se dan de baja de la sociedad.

Más clara es la sentencia del Tribunal Supremo (Sala de lo Civil) de 6 de febrero de $2014^{54}$ a favor de la imputación de deuda bancaria, siempre que se trate de deuda no compensada y no de cantidades pendientes de pago por la financiación de inversio-

\section{RJ\1987\1477.}

53. JUR\2010\369748.

54. La Ley 10446/2014, sentencia comentada por MARÍN HITA, L.: "Sentencia de 6 de febrero de 2014. Cooperativa de Castilla-La Mancha: criterios para la determinación de la liquidación a que tiene derecho el socio que causa baja”, Cuadernos Civitas de Jurisprudencia Civil, no 96, 2014, pp. 215 y ss. 
nes de la Cooperativa. Pero no excluye con carácter general la posibilidad de imputar el pago de cantidades pendientes por la financiación de la Cooperativa, en casos en que el socio hubiese roto su compromiso de permanencia o hubiese participado en el acuerdo para realizar las inversiones o se hubiese obligado a ello. Estos argumentos no son considerados por el Tribunal Supremo en el caso concreto porque su base fáctica no fue alegada en la contestación a la demanda ${ }^{55}$. Sin duda, la solución hubiera sido otra de aplicarse la Ley actual de Cooperativas de Castilla-La Mancha. Además, como bien dice el Tribunal Supremo, aun sin previsión legal expresa, la solución también hubiera podido ser la de admitir dichas deducciones por inversiones y por deuda y obligaciones de la cooperativa pendientes de pago, puesto que no se entra en dicha cuestión por no haberse planteado en las instancias judiciales anteriores.

En mi opinión, existen argumentos más que suficientes para imputar a los socios que causen baja deudas aún no pagadas o liquidadas cuando ellos intervinieron en su adopción. El principio de puertas abiertas no debe ser un instrumento para permitir el abuso de los socios que dejan la cooperativa cuando no es de su interés por las pérdidas provocadas con su aquiescencia mientras permanecían en la cooperativa. Si los socios de la sección han sido convocados a la asamblea y en esta se ha tomado una decisión de inversión, aunque los socios no formalicen un contrato, debe entenderse que han participado en su adopción.

55. Por su interés, se reproducen a continuación los números 5 y 6 del Fundamento de Derecho Undécimo de la sentencia citada: 5.- "Si lo que se pretende deducir es la deuda pendiente por la financiación de determinadas inversiones, como parece desprenderse de la explicación que de esta partida dan las partes, y la propia sentencia de primera instancia (cuantía que «resulta de las inversiones realizadas por la Cooperativa y pendientes de pago según el último balance», se afirma), el art. 61 de la ley autonómica permite deducir las pérdidas no compensadas, pero no las cantidades pendientes de pago por la financiación de inversiones de la Cooperativa. (...) Mientras los demandantes fueron socios, la Cooperativa hubo de realizar los pagos correspondientes a ese período de la financiación de las inversiones. Tales pagos determinaron los resultados económicos de la cooperativa en esos ejercicios, que han repercutido en los hoy demandantes, por cuanto se les han deducido las pérdidas producidas hasta la finalización del ejercicio en que se dieron de baja en la Cooperativa, y en la producción de esas pérdidas influyó haber realizado, entre otros, los pagos de las cuotas de la financiación de las inversiones. No existe base legal para pretender que, además, se les deduzca la parte que queda todavía por abonar de tal financiación, cuyo corresponderá a un periodo durante el que los demandantes no podrán disfrutar ya de tales inversiones. 6.- Los argumentos dados por la recurrida respecto a que fueron los hoy demandantes quienes acordaron realizar las inversiones o que la ley prevé que el incumplimiento mínimo de permanencia no exime al socio de responsabilidad frente a terceros o con la cooperativa por inversiones realizadas y no amortizadas, no pueden ser tomados en consideración, pues parten de una base fáctica diferente a la que la Audiencia ha usado para adoptar el pronunciamiento cuestionados...”. 


\section{Conclusiones}

La posibilidad de imputar pérdidas a los socios de una sección que superen las aportaciones realizadas es una cuestión de orden interno, que afecta a las relaciones de los socios con la sociedad cooperativa. Las normas legales y los preceptos estatutarios que regulan la responsabilidad de los socios por las deudas sociales establecen las reglas de responsabilidad externa de los socios, esto es, de la responsabilidad frente a los terceros que reclamen por las deudas sociales. Nada, o poco, aclaran respecto de la responsabilidad interna de los socios de la sección frente a la cooperativa o respecto del reparto de las pérdidas entre la sociedad cooperativa y los socios. En esta tesitura, no existe en el plano de los principios ningún obstáculo a que la limitación o exclusión de responsabilidad de los socios frente a terceros coexista con la responsabilidad ilimitada de los socios frente a la cooperativa por dichas deudas o por pérdidas, si bien ya son varias las leyes autonómicas que limitan en el ámbito interno la imputación de pérdidas a las aportaciones realizadas.

La autonomía de gestión de las secciones, la necesidad de que su actuación no perjudique a los socios de la cooperativa que no formen parte de ellas, y la asunción por los socios de la responsabilidad derivada de las operaciones específicas de cada una de las secciones, permite entender que para exigir responsabilidad a los socios de una sección es innecesario que la cooperativa haya realizado desembolsos previos, más bien la cooperativa está obligada a imputar dichas deudas: no es una mera facultad. De este modo, en el caso de una sociedad cooperativa con deudas provenientes de una sección, necesariamente se deben imputar las deudas derivadas de la actividad específica de la sección al patrimonio de esta y al de sus socios si los miembros del órgano de administración actúan con la diligencia exigible. Además, la cooperativa podrá exigir dichas cantidades en cualquier momento sin necesidad de esperar a que el socio cause baja.

En caso de baja de socios de una sección, la cooperativa debe exigirles la deuda y pérdidas originadas por la actividad específica de la sección, de manera proporcional a la actividad cooperativizada del socio. De lo contrario, en detrimento de los socios que permanecen en la sección y siguen asumiendo el riesgo de su actividad específica y sus deudas con terceros, se facilitaría la huida de la responsabilidad universal del socio de la sección frente a la cooperativa por la aplicación del principio de puertas abiertas sin ningún tipo de cautelas.

Dicho lo anterior, no ha de hacerse distinción por la naturaleza de las deudas de la cooperativa, o de la sección, que se pretendan imputar a los socios y, por tanto, nada impide que la deuda imputable sea bancaria, incluyendo los costes de financiación. 


\section{Bibliografía}

ALFONSO SÁNCHEZ, R.: "Sociedad y socios como legitimados activos en la solicitud de declaración de concurso de sociedades cooperativas", Revista de Derecho de Sociedades (RdS), no 43, 2014, pp. 85-117.

ALFONSO SÁNCHEZ, R.: "Régimen de responsabilidad de los socios". En: La Ley 27/1999, de 16 de julio, de cooperativas. Veinte años de vigencia y resoluciones judiciales (1999.2019) (dirs. ALFONSO SÁNCHEZ, R., CAVAS MARTÍNEZ, F., NAVARRO EGEA, M. \& VALERO TORRIJOS, J.), Editorial Aranzadi, Cizur Menor, 2021, pp. 463-511.

BORJABAD GONZALO, P.J.: Manual de Derecho cooperativo. General y catalán, J.M. Bosch Editor, Barcelona, 1993.

CAMPOS CLIMENT, V., FAJARDO GARCÍA, I.G. \& SANCHIS PALACIO, J.R.: "Triple justificación de las secciones de crédito de las cooperativas agrarias de la Comunidad Valenciana: jurídica, económica y social”, CIRIEC-España, Revista de Economia Pública Social y Cooperativa, no 54, 2006, p. 129-165.

COSTAS COMESAÑA, J.: "Capítulo VIII. Capital social, aportaciones y régimen económico". En: Régimen jurídico de las sociedades cooperativas catalanas (Adaptado a la Ley 12/2015, de 9 de julio, de Cooperativas de Cataluña) (dir. ALFONSO SÁNCHEZ, R.), Atelier Editorial, Barcelona, 2020, pp. 221-278.

DOMÍNGUEZ CABRERA, M.P.: "Responsabilidad patrimonial de las 'secciones' de las cooperativas en proceso concursal", Aranzadi Civil: Revista Doctrinal, no 3, 2010, pp. 49-75.

FAJARDO GARCÍA, I.G.: La gestión económica de la cooperativa: responsabilidad de los socios, Editorial Tecnos, Madrid, 1997.

FAJARDO GARCÍA, I.G.: "Las secciones de crédito en el ordenamiento jurídico español”, CIRIEC-España, Revista de Economía Pública Social y Cooperativa, no 32, 1999, pp. 9-37.

GADEA SOLER, E.: "Las secciones de las cooperativas". En: Cooperativas agrarias $y$ sociedades de transformación (coords. VARGAS VASSEROT, C. \& PULGAR EZQUERRA, J.), Editorial Dykinson, Madrid, 2006, pp. 605-630.

GADEA SOLER, E., SACRISTÁN BERGIA, F. \& VARGAS VASSEROT, C.: Régimen jurídico de la sociedad cooperativa del siglo XXI. Realidad actual y propuestas de reforma, Editorial Dykinson, Madrid, 2009. 
GIRGADO PERANDONES, P.: "Capítulo IX. Las secciones de crédito de las sociedades cooperativas catalanas". En: Régimen jurídico de las sociedades cooperativas catalanas (Adaptado a la Ley 12/2015, de 9 de julio, de Cooperativas de Cataluña) (dir. ALFONSO SÁNCHEZ, R.), Atelier Editorial, Barcelona, 2020, pp. 279300.

LATORRE RUIZ, J.: "El oportunismo de las secciones de comercialización en las sociedades cooperativas agrarias", Revista de Estudios Jurídicos, no 19, 2019, pp. 240-251. https://revistaselectronicas.ujaen.es/index.php/rej/article/view/5153

LLOBREGAT HURTADO, M.L.: "Posición jurídica del socio (I): clases de socios, adquisición de la condición de socio, derechos y obligaciones y responsabilidad". En: La Sociedad Cooperativa en la Ley 27/1999, de 16 de julio, de Cooperativas (coord. ALONSO ESPINOSA, F.J.), Editorial Comares, Granada, 2001, pp. 129-144.

MARÍN HITA, L.: "Sentencia de 6 de febrero de 2014. Cooperativa de Castilla-La Mancha: criterios para la determinación de la liquidación a que tiene derecho el socio que causa baja”, Cuadernos Civitas de Jurisprudencia Civil, no 96, 2014, pp. 215-240.

MORILLAS JARILLO, M.J.: "Secciones (art. 12 LSCA)". En: Retos y oportunidades de las sociedades cooperativas andaluzas ante su nuevo marco legal. Comentario a la Ley 14/2011 de Sociedades Cooperativas Andaluzas y a su Reglamento de desarrollo (Decreto 123/2014) (dirs. MORILLAS JARILLO, M.J., VARGAS VASSEROT, C. \& CANO ORTEGA, C.), Editorial Dykinson, Madrid, 2017, pp. 85-103.

MORILLAS JARILLO, M.J. \& FELIÚ REY, M.I.: Curso de cooperativas, T. I., Editorial Tecnos, Madrid, 2018.

MUÑOZ VIDAL, A.: "Secciones de Cooperativas: su personalidad jurídica”, Mundo Cooperativo, no 699-700, 1978, p. 9.

PANIAGUA ZURERA, M.: Tratado de Derecho Mercantil, t. XII: La sociedad cooperativa. Las sociedades mutuas de seguros y las mutualidades de previsión social, Marcial Pons, Ediciones Jurídicas y Sociales, Madrid, 2005.

PANIAGUA ZURERA, M.: "Régimen económico". En: Tratado de Derecho de Sociedades coperativas (dir. PEINADO GARCÍA, J.I.), T. I, Editorial Tirant Lo Blanch, València, 2018, pp. 804-899.

PULGAR EZQUERRA, J.: "La pérdida de la condición de socio en el marco cooperativo: su baja y expulsión”. En: Estudios de Derecho Mercantil (coords. SÁENZ GARCÍA DE ALBIZU, J.C., OLEO BANET, F. \& MARTÍNEZ FLOREZ A.), Editorial Civitas, Cizur Menor, 2010, pp. 1039-1082.

SANTOS MARTÍNEZ, V.: "Las secciones de las cooperativas en el derecho español”, Revista Jurídica de Catalunya (RJC), no 79(4), 1980, pp. 957-1010. 
VARGAS VASSEROT, C., GADEA SOLER, E. \& SACRISTÁN BERGIA, F.: Derecho de las sociedades cooperativas. Régimen económico, integración, modificaciones estructurales y disolución, La Ley, Madrid, 2017.

VICENT CHULIÁ, F.: Introducción al Derecho mercantil, vol. I, Editorial Tirant lo Blanch, València, 2012. 